\title{
Piperine enhances carbohydrate/fat metabolism in skeletal muscle during acute exercise in mice
}

\author{
Jisu Kim ${ }^{1}$ Kang-Pa Lee ${ }^{2}$, Dae-Won Lee ${ }^{3}$ and Kiwon Lim ${ }^{1,4^{*}}$
}

\begin{abstract}
Background: Exercise promotes energy metabolism (e.g., metabolism of glucose and lipids) in skeletal muscles; however, reactive oxygen species are also generated during exercise. Various spices have been reported to have beneficial effects in sports medicine. Here, we investigated the effects of piperine, an active compound in black pepper, to determine its effects on metabolism during acute endurance exercise.

Methods: ICR mice $(n=18)$ were divided into three groups: nonexercise $(C O N)$, exercise $(E X)$, and exercise with piperine $(5 \mathrm{mg} / \mathrm{kg}$ ) treatment (EP). Mice were subjected to enforced exercise on a treadmill at a speed of $22 \mathrm{~m} / \mathrm{min}$ for $1 \mathrm{~h}$. To evaluate the inflammatory responses following exercise, fluorescence-activated cell sorting analysis was performed to monitor changes in $\mathrm{CD}^{+}$cells within the peripheral blood mononuclear cells (PBMCs) of mice. The expression levels of metabolic pathway components and redox-related factors were evaluated in the soleus muscle by reverse transcription polymerase chain reaction and western blotting.

Results: There were no changes in the differentiation of immune cells in PBMCs in both the EX and EP groups compared with that in the CON group. Mice in the EX group exhibited a significant increase in the expression of metabolic pathway components and redox signal-related components compared with mice in the CON group. Moreover, mice in the EP group showed greater metabolic (GLUT4, MCT1, FAT/CD36, CPT1, CS) changes than mice in the EX group, and changes in the expression of redox signal components were lower in the EP group than those in the EX group.

Conclusion: Our findings demonstrate that piperine promoted beneficial metabolism during exercise by regulating carbohydrate/fat metabolism and redox signals. Therefore, piperine may be a candidate supplement for improvement of exercise ability.
\end{abstract}

Keywords: Acute endurance exercise, Piperine, Carbohydrate metabolism, Fat metabolism, Antioxidant

\section{Background}

The western diet generally includes excessive caloric intake. Moreover, many individuals have adopted a sedentary lifestyle, including little or irregular physical activity, leading to increased rates of obesity and mortality [1]. The World Health Organization (WHO) recommends that individuals exercise daily to alleviate obesity and

\footnotetext{
* Correspondence: exercise@konkuk.ac.kr

${ }^{1}$ Physical Activity \& Performance Institute, Konkuk University, 120 Neungdong-ro, Gwangjin-gu, Seoul 05029, Republic of Korea

${ }^{4}$ Department of Physical Education, Laboratory of Exercise Nutrition, Korea University, 120 Neungdong-ro, Gwangjin-gu, Seoul 143-701, Republic of Korea

Full list of author information is available at the end of the article
}

improve health [2]. Therefore, appropriate research is needed to fully elucidate the effects of exercise on health and the appropriate type of exercise that should be adopted to ensure a healthy lifestyle.

Endurance exercise demands consumption of energy through increased metabolism, leading to reduction of body weight [3, 4]. Moreover, endurance exercise involves generation of reactive oxygen species (ROS) during energy synthesis. Excessive ROS generation from high-intensity endurance exercise can lead to muscle rupture and immune system over-reaction [5]. Additionally, continuous exercise increases immune system function by activating immune cells, including $\mathrm{T}$ cells, natural killer (NK) cells, 
and T helper (Th) cells [6, 7]. Despite these findings, additional work is still needed to determine the effects of immune system activation and exercise on the generation of ROS. Low levels of ROS augment metabolism, thereby enhancing cell proliferation and differentiation, whereas the presence of high levels of ROS induces cell death $[8,9]$. Enzymes within the redox signaling cascade function to maintain homeostasis despite ROS generation. For example, nicotinamide adenine dinucleotide phosphate (NADPH)-oxidase (NOX), which is encoded by NOX family genes [10], is a key enzyme involved in ROS generation. NOX1 is expressed in a variety of cells and promotes ROS generation $[10,11]$. Oxidative stress from the generated ROS is eliminated by antioxidant signaling and enzymes involved in redox homeostasis, such as manganese superoxide dismutase (Mn-SOD), catalase, zinc superoxide dismutase (Zn-SOD), and Ape/Ref-1 [12, 13]. In particular, Ape/Ref-1 is a multifunctional protein with endonuclease, transcription factor, and antioxidant functions. However, the effects of Ape/Ref- 1 on the maintenance of redox homeostasis and immune system function in the context of excessive exercise have not yet been elucidated.

Skeletal muscles have important metabolic energy functions based on the generation and utilization of energy sources from the phosphagen system, glycolysis, and the anaerobic system. Carbohydrate and fat metabolism occur in the muscles during exercise [14]. Skeletal muscles generate energy using energy sources source such as glucose, lactate, and fatty acids [4, 15]. These components are transported into muscle cells via specific metabolic transporters, including glucose transporter type 4 (GLUT4), monocarboxylate transporter 1 (MCT1), and FAT/CD36 [16, 17]. The energy required for transport is generated through the tricarboxylic acid (TCA) cycle in the mitochondria $[18,19]$. In particular, carnitine palmitoyltransferase 1 (CPT1), which is present in the mitochondrial outer membrane and plays an important role in fat metabolism, transports long-chain acetyl-CoA, which is generated from fatty acids in the inner mitochondrial membrane [20, 21]. In addition, citrate synthase (CS), which converts acetyl-Co-A to citrate before entering the TCA cycle, is also important in the production of energy [22, 23].

In both athletes and individuals who are exercising for the first time, strenuous exercise can cause various types of damage in the body. Therefore, an effective exercise routine for each person is necessary, taking into account nutritional and physiological changes. Accordingly, recent research has focused on the role of health supplements in promoting the beneficial effects of exercise. Piperine, one of the main components of pepper, has been shown to have diverse biological activities, including anti-inflammatory, antioxidant, anti-atherosclerotic anti-obesity effects and blood lipid improvement in a variety of cell types and animal models. However, the effects of piperine on endurance exercise and changes in skeletal muscles have not yet been established.

Accordingly, in this study, we determined the effects of piperine on muscles during endurance exercise in a mouse model.

\section{Methods}

\section{Animal experiment}

Six-week-old male ICR mice $(n=18)$ were purchased from Orient Bio Inc. (Seongnam, Korea). All mice were housed in standard plastic cages under controlled conditions of humidity $(50 \%)$ and temperature $\left(23 \pm 1{ }^{\circ} \mathrm{C}\right)$ with an alternating 12-h light/dark cycle. Mice were acclimated to the laboratory housing conditions for 7 days. Mice were randomized into three groups: nonexercise $(\mathrm{CON})$, exercise $(\mathrm{EX})$, and exercise with piperine treatment (EP). Piperine was dissolved in dimethyl sulfoxide (DMSO; via oral gavage, in a volume of $50 \mu \mathrm{L}$ ) and administered to the EP group at $5 \mathrm{mg} / \mathrm{kg}$; the $\mathrm{CON}$ group and EX groups were treated with distilled water via oral administration at $30 \mathrm{~min}$ before acute endurance exercise. All experimental procedures were performed at the Animal Experiment Research Center of Konkuk University. This study was conducted in accordance with the ethical guidelines of the Konkuk University Institutional Animal Care and Use Committee. All mice were adapted to treadmill training (Daejong Systems, Korea) at a fixed intensity $\left(10 \mathrm{~m} / \mathrm{min}, 8^{\circ}\right.$ slope, $\left.10 \mathrm{~min}\right)$ for 3 days. The following protocols were used: $22 \mathrm{~m} / \mathrm{min}, 8^{\circ}$ slope, 60 min (approximately 70\% maximal oxygen consumption $\left.\left[\mathrm{VO}_{2}\right]\right)$ for acute exercise. Blood samples and soleus muscles were collected immediately after exercise.

\section{Fluorescence-activated cell sorting (FACS) analysis}

FACS assays were performed as previously reported [24]. To determine the expression of T-cell-related surface molecules, peripheral blood mononuclear cells (PBMCs) were isolated using a Ficoll-Hypaque gradient (SigmaAldrich, UK). For analysis of cytokine production in differentiated Th1, Th2, and Th17 cells, isolated PBMCs were stained with anti-CD3-PerCP, anti-CD4-APC, and/ or anti-CD8-APC-Cy7 antibodies (BioLegend, USA). After washing with FACS buffer $(0.1 \%$ bovine serum albumin $[B S A]$ in phosphate-buffered saline $[\mathrm{PBS}])$, the cells were then stimulated with $50 \mathrm{ng} / \mathrm{mL}$ phorbol 12 myristate 13-acetate (PMA; Sigma-Aldrich) and $1 \mu \mathrm{g} / \mathrm{mL}$ ionomycin (Sigma-Aldrich) in the presence of Golgistop (BD Biosciences, USA) for $4 \mathrm{~h}$ at $37^{\circ} \mathrm{C}$. The stimulated cells were washed with FACS buffer and fixed for 10 min with $4 \%$ paraformaldehyde. After fixation, the cells were permeabilized with FACS Perm 2 according to the manufacturer's instructions (BD Biosciences, USA) 
and stained with appropriate fluorochrome-conjugated antibodies, including anti-mouse interferon (IFN)- $\gamma$ conjugated with fluorescein isothiocyanate (FITC; BD Biosciences, USA) and anti-mouse interleukin (IL)-17A conjugated with phycoerythrin (eBioscience, Germany) antibodies using isotype antibodies as controls. All data were collected on a FACSCalibur flow cytometer (BD Biosciences) and analyzed using FlowJo software (Tree Star Inc., USA).

Total RNA isolation and reverse transcription (RT)polymerase chain reaction (PCR)

Total RNA isolation and RT-PCR analyses were performed as previously reported [25]. The soleus muscles of each mouse were harvested, and total RNA was isolated from cells using TRI-reagent (GenDEPOT, Korea). Next, cDNA was synthesized using $1.0 \mu \mathrm{g}$ of total RNA with oligo dT(18mer). For PCR, $1 \mu \mathrm{L}$ of $\mathrm{cDNA}$ was subjected to predenaturation at $95{ }^{\circ} \mathrm{C}$ for 3 min, 35 cycles of denaturation at $94{ }^{\circ} \mathrm{C}$ for $1 \mathrm{~min}$, primer annealing at the optimal temperature for $1 \mathrm{~min}$, and extension at $72{ }^{\circ} \mathrm{C}$ for $1 \mathrm{~min}$, followed by a final extension at $72{ }^{\circ} \mathrm{C}$ for $10 \mathrm{~min}$. The following primers were used for PCR: GLUT4 $\left(60{ }^{\circ} \mathrm{C}\right.$; sense primer, $5^{\prime}$-AACTTGGCATTGTGGAAGG-3', and antisense primer, 5' -ACACATTGGGGGTAGGAACA-3'), MCT1 $\left(60{ }^{\circ} \mathrm{C}\right.$; sense primer, 5'-GCTGGAGGTCCTAT CAGCAG-3', and antisense primer, 5'-AGTTGAAAG CAAGCCCAAGA-3'), CD36 $\left(60{ }^{\circ} \mathrm{C}\right.$; sense primer, $5^{\prime}$ GGCCAAGCTATTGCGACAT-3', and antisense primer, 5'-CAGATCCGAACACAGCGTAGA-3'), CPT1 $\left(60{ }^{\circ} \mathrm{C}\right.$; sense primer, $5^{\prime}$-ATCATGTATCGCCGCAAACT-3', and antisense primer, 5'-CCATCTGGTAGGAGCACATGG$\left.3^{\prime}\right), C S\left(60{ }^{\circ} \mathrm{C}\right.$; sense primer, 5'-CAAGTCATCTACGC CAGGGAC3', and antisense primer, 5'-CAAAGCGTCTC CAGCTAACCA-3'), and GAPDH, sense primer, 5'-GG CATTGCTCCTCAATGACAA-3', and antisense primer, 5'-TGTGAGGGAGATGCTCAGTG-3'. PCR products were separated by $2.0 \%$ agarose gel electrophoresis and visualized by staining with ethidium bromide.

\section{Tissue processing and immunoblotting assay}

Immunoblotting was performed as previously reported [26]. Tissue was homogenized in ice-cold cell lysis buffer (50 mM Tris- $\mathrm{HCl}, \mathrm{pH} 7.4,150 \mathrm{mM} \mathrm{NaCl}, 0.25 \%$ deoxycholic acid, 1\% NP-40, $1 \mathrm{mM}$ ethylenediaminetetraacetic acid [EDTA], and protease inhibitors, including $1 \mathrm{mM}$ phenylmethylsulfonyl fluoride [PMSF], $1 \mathrm{~g} / \mathrm{mL}$ aprotinin, $1 \mathrm{~g} /$ $\mathrm{mL}$ leupeptin, $1 \mathrm{mM} \mathrm{Na} \mathrm{VO}_{4}$, and $1 \mathrm{mM} \mathrm{NaF}$ ), and homogenates were agitated for $1 \mathrm{~h}$ at $4{ }^{\circ} \mathrm{C}$. Homogenates were then centrifuged at $13,000 \times g$ at $4{ }^{\circ} \mathrm{C}$ for $15 \mathrm{~min}$, and the supernatant was collected and stored at $80{ }^{\circ} \mathrm{C}$ until further analysis. To analyze protein expression, we performed western blotting using specific antibodies. Briefly, $30 \mu \mathrm{g}$ of protein from each group was boiled, separated by electrophoresis on $12 \%$ acrylamide gels, and then transferred onto polyvinylidene difluoride membranes in transfer buffer at $4{ }^{\circ} \mathrm{C}$ for $2 \mathrm{~h}$. The membranes were blocked with $5 \%$ BSA in Tris-buffered saline (TBS) at room temperature for $1 \mathrm{~h}$ and then washed in TBS with $0.1 \%$ Tween 20 (TBS/T). The membranes were incubated overnight at $4{ }^{\circ} \mathrm{C}$ with specific antibodies against NOX-1, Ape/Ref- 1 , MnSOD, and $\beta$-actin (1:1000 dilution [Santa Cruz, USA]). The membranes were washed with TBS/T, followed by incubation with IgG secondary antibodies conjugated with horseradish peroxidase (1:1000 dilution [Santa Cruz, USA]). The expression levels of the proteins were analyzed using chemiluminescence (ECL Plus Kit; Amersham Pharmacia Biotech). Developed protein bands were visualized and quantified using Image J software (NIH, Bethesda, MD, USA).

\section{Data analysis}

Data were expressed as the mean \pm standard error of the means (SEMs). Statistical evaluation of the data was performed using GraphPad Prism, version 5.0 (GraphPad Software, USA). Student's $t$-tests and one-way analysis of variance (ANOVA) with Tukey's post-hoc tests were used to compare the data. Differences with $P<0.05$ were considered statistically significant.

\section{Results}

Effects of piperine on acute endurance exercise-induced immune responses

Physical exercise can enhance the activity of immune responses, including both the innate and adaptive immune responses [27]. Therefore, we investigated the effects of piperine on acute endurance excise by evaluating differentiated Th1, Th2, and Th17 cells in PBMCs using FACS analysis. The one-time acute endurance excise experiment is depicted in Fig. 1b. As shown in Fig. 2, there were no changes in IFN- $\gamma$ or IL-17 expression in mice in the EX or EP groups compared with those in the control group.

\section{Effects of piperine on carbohydrate/fat metabolism in soleus muscles from mice after acute endurance exercise}

The skeletal muscle system represents an accessible metabolic energy source, providing small carbohydrates during exercise [15]. Therefore, to determine the effects of piperine on the energy source used during acute endurance exercise, we evaluated GLUT4, MCT1, FAT/CD36, CPT1, and CS mRNA expression by RT-PCR. As shown in Fig. 3a, the expression levels of GLUT4 and MCT1 mRNAs were higher in the EP group than in the EX and CON groups. Moreover, as shown in Fig. 3b, FAT/CD36, CPT1, and $C S$ mRNAs were also significantly upregulated by exercise and piperine administration. Besides, we performed the following additional experiments. We checked the protein (GLUT4, FAT/36 and CPT1) levels using the western blot assay. As show in Additional file 1: Figure S1, these results showed similar expression of genes and proteins. 


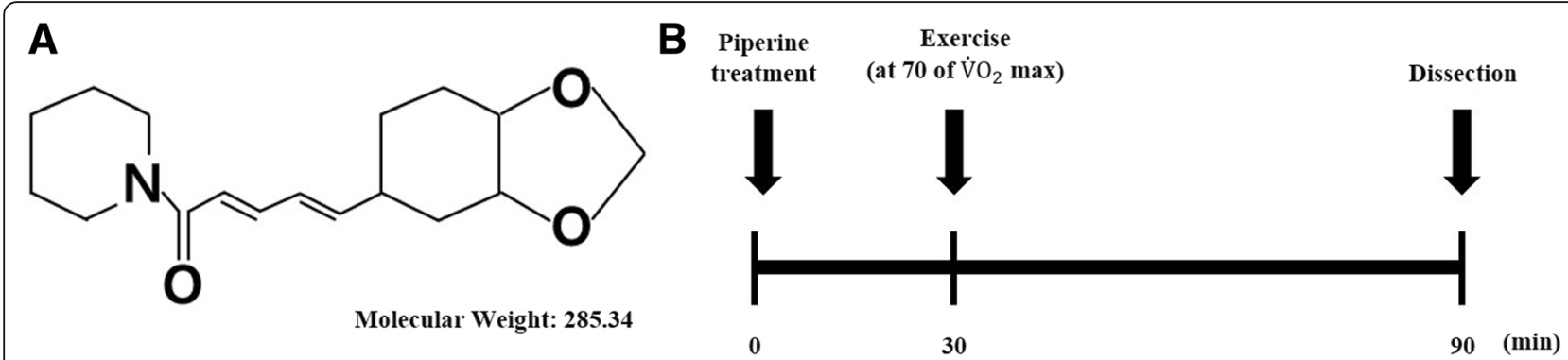

Fig. 1 Study design. a Structure of piperine $\left(\mathrm{C}_{17} \mathrm{H}_{19} \mathrm{NO}_{3}\right.$; molecular weight: $\left.285.34 \mathrm{Da}\right)$. b Study design showing the exercise protocol. Mice were administered $5 \mathrm{mg} / \mathrm{kg}$ piperine orally $30 \mathrm{~min}$ prior to running on a treadmill for $1 \mathrm{~h}$. After exercise, mice were sacrificed, and tissues were collected

Effects of piperine on antioxidant enzymes in soleus muscles from mice after acute endurance exercise High-intensity exercise-induced oxidative stress usually involves elimination mechanisms and homeostasis systems [28]. Therefore, to examine whether piperine inhibited ROS generation, we measured the expression levels of antioxidant enzymes by immunoblotting. As shown in Fig. 4, NOX-1, Ape/Ref-1, and Mn-SOD levels were significantly increased in soleus muscles following exercise as compared with those in the control group. However, piperine administration significantly reduced the expression levels of NOX-1, Ape/Ref-1, and Mn-SOD compared with those in the control group. In addition, we checked the results of L6 cell in vitro as follows. To explore the effect of piperine on H2O2-stimulated L6 cell, we performed the three experiments such as cell observed assay and reverse transcription polymerase chain reaction (RTPCR) analysis. Cell morphology change was observed by inverted microscope for $1 \mathrm{~h}$, respectively. RT-PCR analysis was used to determine CAT, NOX-1, APE/REF1 and MnSOD. As show in Additional file 2: Figure S2A, the cell morphology for $1 \mathrm{~h}$ is not altered in all conditions (untreated, $100 \mu \mathrm{M} \mathrm{H} 2 \mathrm{O} 2$, and $100 \mu \mathrm{M} \mathrm{H} 2 \mathrm{O} 2$ with peprine $(10 \mathrm{uM})$. H2O2 significantly increases the expression levels of mRNA CAT, NOX-1, APE/REF1 and Mn-SOD whereas piperine significantly regulated those-signals.

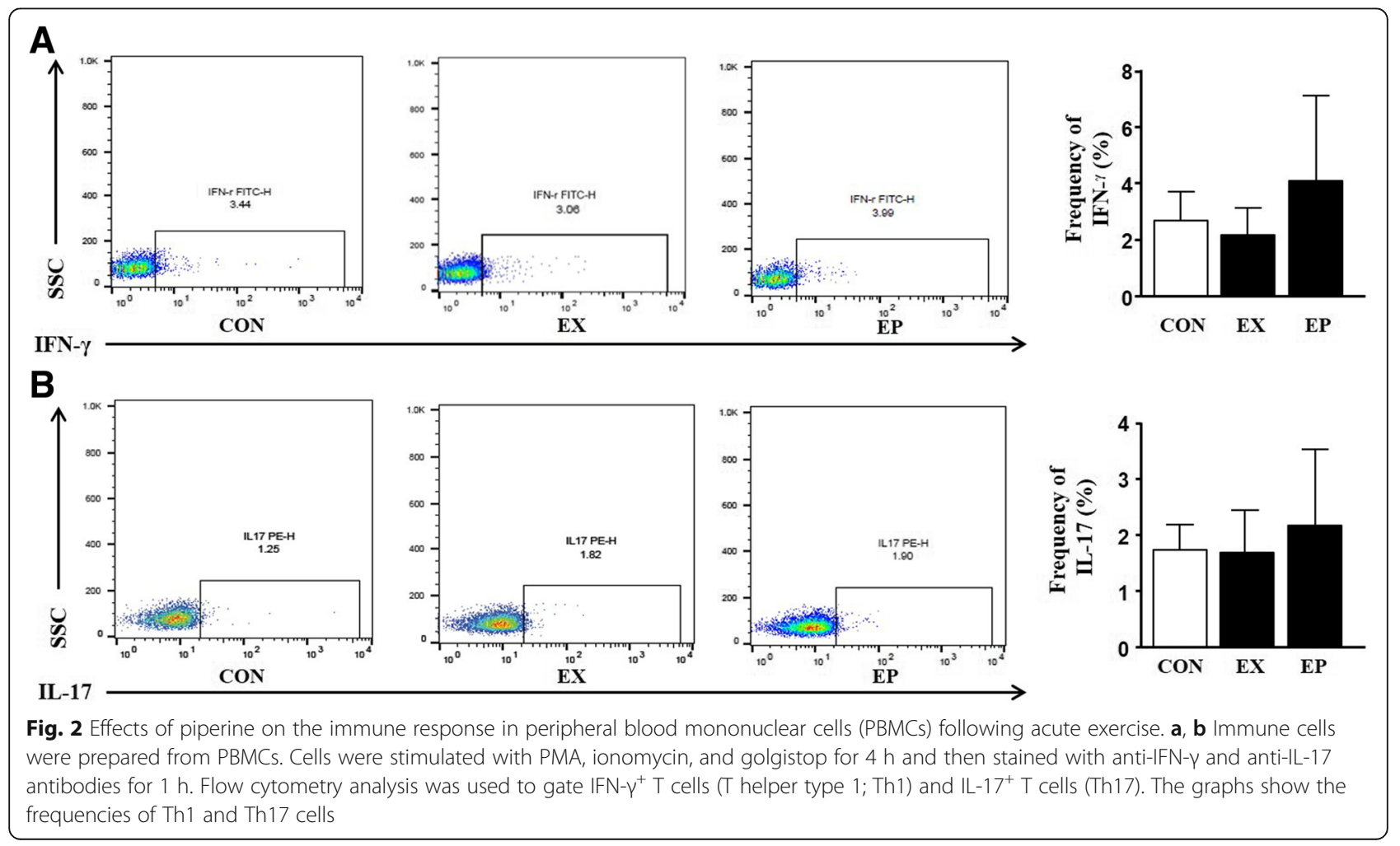




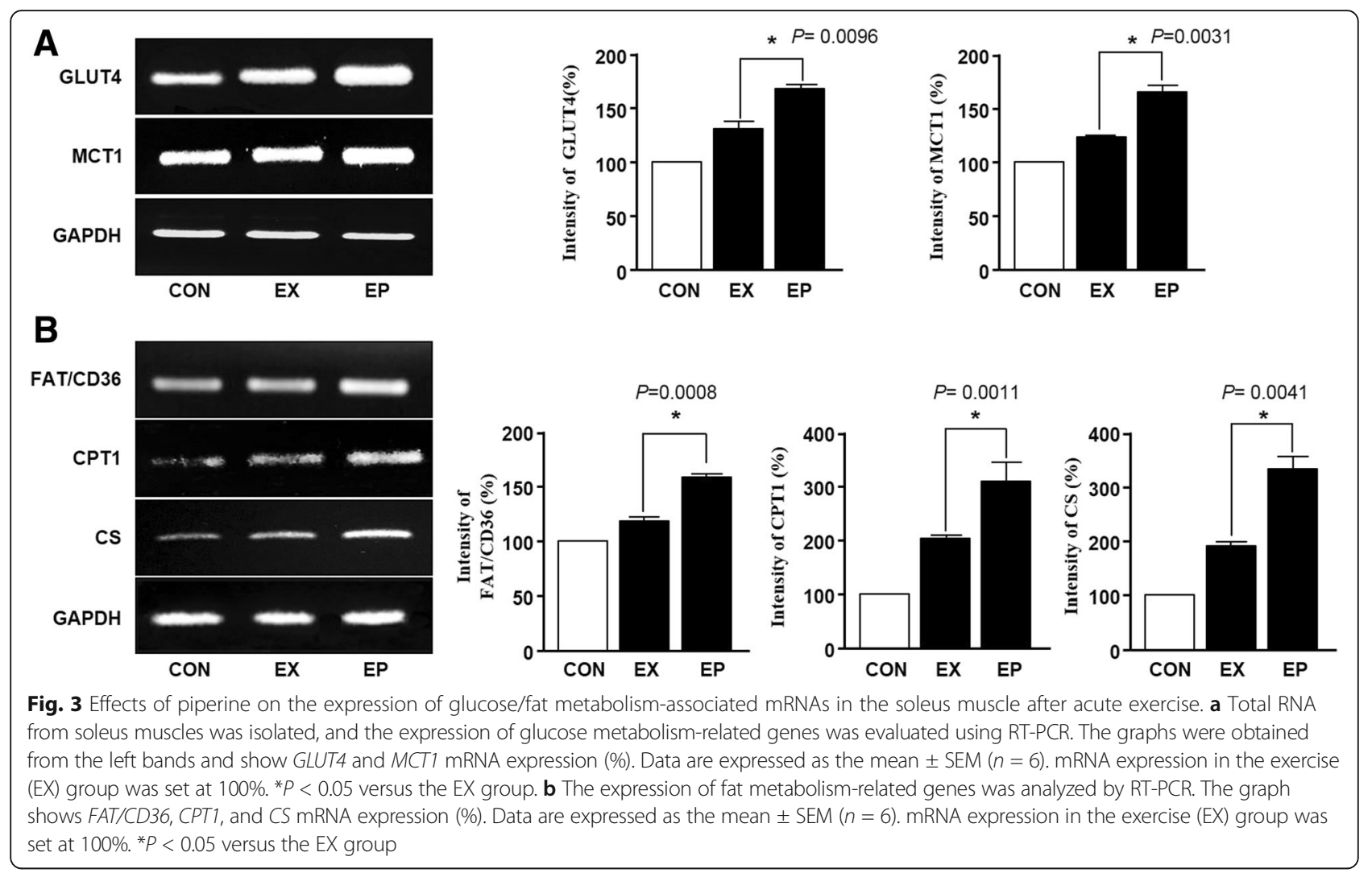

\section{Discussion}

Although piperine has been shown to have antiinflammatory, anticancer, anti-atherosclerotic, and antioxidant effects and to inhibit lipid synthesis, the effects of piperine on carbohydrate/fat metabolism and skeletal muscle damage during endurance exercise have not been evaluated. Here, we provide evidence of the role of piperine in mediating carbohydrate/fat metabolism in skeletal muscle in acute endurance exercise for the first time. Our findings demonstrate that piperine treatment enhanced fat/carbohydrate metabolism in skeletal muscle and that piperine administration decreased the expression of NOX1 and antioxidant enzymes, such as
Mn-SOD and Ape/Ref-1, after acute exercise. Moreover, acute endurance exercise did not alter immune responses, with or without piperine treatment. These results imply that piperine regulated muscle damage and energy metabolism during acute endurance exercise.

Regular exercise can have beneficial effects on health; however, high-intensity physical exercise or excessive exercise can induce muscle degeneration and inflammation $[28,29]$. Recently, sports science and nutrition experts have suggested that short-term supplementation with antioxidants may provide beneficial effects on health and reduce damage and inflammation after exercise [30]. Based on our data, there were no changes in
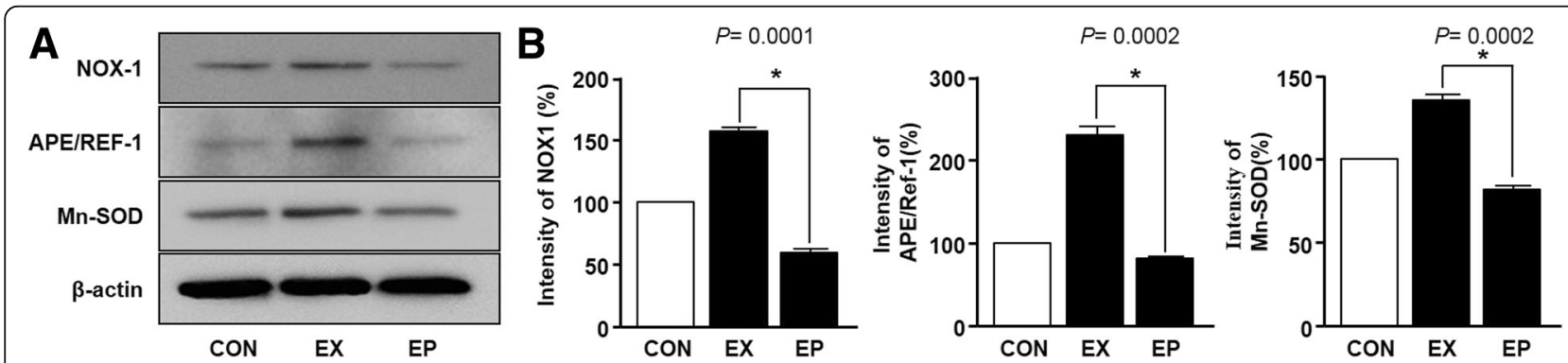

Fig. 4 Effects of piperine on the expression of reactive oxygen species (ROS)-regulated mRNA in the soleus muscle after acute exercise. a Soleus muscles were collected after exercise, and protein expression was evaluated using immunoblotting. $\mathbf{b}$ The graphs represent the intensities of NOX1, APE/Ref-1, and Mn-SOD bands (\%). Data are expressed as the mean \pm SEM $(n=6)$. The band intensity in the exercise (EX) group was set at $100 \%$. ${ }^{*} P<0.05$ versus the EX group 
immune responses in PBMCs among the three groups (control, exercise, and exercise after piperine administration). These results imply that the performance in the EP group was not related to the innate immune response during acute exercise after short-term administration of piperine. Therefore, we suggest that piperine may be administered safely during exercise.

Exercise is tightly associated with the generation of ROS in the skeletal muscle [30]. During exercise, ROS are produced through energy-generating metabolic processes, which consume high levels of oxygen. We found that NOX1, Mn-SOD, and Ape/ref.-1 expression levels were decreased in mice administered piperine and subjected to acute exercise compared with those in exercised mice without piperine administration. These results imply that piperine provided scavenging activity against superoxide generation, consistent with a previous study [31].

Because of the increased metabolic rate and energy demand associated with exercise, the oxidization of both fat and carbohydrates must be activated simultaneously [4]. Previous studies have reported that FAT/CD36, CPT1, and CS are key components of the molecular machinery required for regulating fat oxidation in skeletal muscle [32, 33]. During exercise, increased glycolysis and subsequent production and accumulation of lactate necessitate increased expression of GLUT4 and MCT1 [16]. Our data also indicate that the expression levels of fat metabolism-related genes, such as $F A T / C D 36, C P T 1$, and $C S$, were significantly increased in the skeletal muscle following exercise with or without short-term piperine administration. A previous study reported that piperine was supplemented in different doses $(20,30$ and $40 \mathrm{mg} / \mathrm{kg}$ ) through administration of a high-fat diet (HFD) for 42 days to experimental rats. Piperine significantly reduced the concentration of plasma and liver lipids in obese rats to near normal levels, and HDL was elevated [34]. Thus, piperine ingestion may influence fat metabolism.

Moreover, our data indicate that the transcription of GLUT4 and MCT1 was promoted by acute exercise after short-time administration of piperine. Therefore, we suggest that piperine, an active component of black pepper, may be used as a sports supplement for improving exercise ability and adaption.

However, a limitation of this study is that we did not use the mice only treated with piperine as a control group. This is because we 1) intended to differentiate our study from previous studies and 2) wanted to confirm the effects of supplementation of piperine in acute exercise.

AMP-activated protein kinase (AMPK) is an enzyme that controls key players of metabolic pathways, such as glycolysis and fatty acid oxidation [35, 36]. Although we did not evaluate AMPK signaling in this study, piperine may regulate the AMPK pathway, as shown in previous reports [37] and supported by our current data. Previously, several in vitro and in vivo studies attempted to determine the mechanisms through which piperine affects fat metabolism [38-41]. Overall, our results show that piperine treatment can improve the carbohydrate/fat metabolism in skeletal muscle during acute exercise. Further studies are needed to clarify the long-term effects of piperine on exercise endurance capacity in athletes.

\section{Conclusion}

In conclusion, our findings suggest that piperine improve beneficial energy metabolism during exercise by regulating carbohydrate/fat metabolism without stimulating the innate immune response or superoxide generation. Therefore, piperine may have applications as a nutritional supplement for improvement of exercise ability.

\section{Additional files}

Additional file 1: Figure S1. Effects of piperine on the expression of glucose/fat metabolism-associated protein in the soleus muscle after acute exercise. Total protein from soleus muscles was isolated, and the expression of glucose metabolism-related genes was evaluated using western blot. (JPEG $40 \mathrm{~kb}$ )

Additional file 2: Figure S2. Effects of piperine on exogenous hydrogen peroxide (H2O2)-stimulated L6 skeletal muscle cells. L6 cells were treated with piperine $(10 \mu \mathrm{M})$ and presence or absence of $\mathrm{H} 2 \mathrm{O} 2(100 \mu \mathrm{M})$ for 1 h. These morphological changes were observed by inverted microscope (A). Reverse transcription polymerase chain reaction analysis was used to determine CAT, NOX-1, APE/REF1 and Mn-SOD (B). These graphs are presented as mean \pm standard error $(P<0.05)$. (JPEG $230 \mathrm{~kb}$ )

\section{Abbreviations}

AMPK: AMP-activated protein kinase; ANOVA: Analysis of variance; CPT1: Carnitine palmitoyltransferase 1; CS: Citrate synthase; FITC: Fluorescein isothiocynanate; GLUT4: Glucose transporter type 4; IFN: Interferon; IL: Interleukin; MCT1: Monocarboxylate transporter 1; Mn-SOD: Manganese superoxide dismutase; NADPH: Nicotinamide adenine dinucleotide phosphate; NK: Natural killer; NOX: Nicotinamide adenine dinucleotide phosphate; PBMC: Peripheral blood mononuclear cell; PCR: Polymerase chain reaction; PMA: Phorbol 12-myristate 13-acetate; ROS: Reactive oxygen species; RT: Reverse transcription; SEM: Standard error of the mean; TBS: Trisbuffered saline; TBS/T: Tween 20; TCA: Tricarboxylic acid; Th: T helper; ZnSOD: Zinc superoxide dismutase

\section{Acknowledgments}

This paper was supported by the KU Research Professor Program of Konkuk University.

\section{Funding}

This study was supported by the Basic Science Research Program through the National Research Foundation of Korea (NRF) funded by the Ministry of Education (2015R1D1A4A01019776).

\section{Availability of data and materials}

Data are all contained within the article.

\section{Authors' contributions}

JSK contributed to the study conception and experimental design, collected data, and performed analyses. KPL interpreted the data and had primary responsibility for the final content. DWL participated in the study conception. KWL provided advice on the study design and management. All authors 
were involved in editing the manuscript and read and approved the final manuscript.

\section{Competing interests}

The authors declare that they have no competing interests.

\section{Consent for publication}

Not applicable.

\section{Ethics approval}

All experimental procedures were performed at the Animal Experiment Research Center of Konkuk University. This study was conducted in accordance with the ethical guidelines of the Konkuk University Institutional Animal Care and Use Committee.

\section{Publisher's Note}

Springer Nature remains neutral with regard to jurisdictional claims in published maps and institutional affiliations.

\section{Author details}

${ }^{1}$ Physical Activity \& Performance Institute, Konkuk University, 120 Neungdong-ro, Gwangjin-gu, Seoul 05029, Republic of Korea. ${ }^{2}$ Department of Medical Science, School of Medicine Konkuk University, 120 Neungdong-ro, Gwangjin-gu, Seoul 05029, Republic of Korea. ${ }^{3}$ Department of Bio-Science, College of Natural Science, Dongguk University, Dongdae-ro 123, Gyeongju, Gyeongsangbuk-do 38066, Republic of Korea. ${ }^{4}$ Department of Physical Education, Laboratory of Exercise Nutrition, Korea University, 120 Neungdong-ro, Gwangjin-gu, Seoul 143-701, Republic of Korea.

\section{Received: 22 December 2016 Accepted: 7 June 2017}

\section{Published online: 04 July 2017}

\section{References}

1. Tee E. Obesity in Asia: prevalence and issues in assessment methodologies. Asia Pac J Clin Nutr. 2002;11:694-701.

2. Peters SJ, Leblanc PJ. rnrmf. Nutr Metab. 2004;30:1-7.

3. Coggan AR. Plasma glucose metabolism during exercise in humans. Sports Med. 1991;11:102-24.

4. Spriet LL. New insights into the interaction of carbohydrate and fat metabolism during exercise. Sports Med. 2014;44:87-96.

5. Bouzid MA, Filaire E, McCall A, Fabre C. Radical oxygen species, exercise and aging: an update. Sports Med. 2015;45:1245-61.

6. Natale VM, Brenner IK, Moldoveanu Al, Vasiliou P, Shek P, Shephard RJ Effects of three different types of exercise on blood leukocyte count during and following exercise. Sao Paulo Med J. 2003;121:9-14.

7. LaVoy EC, Nieman DC, Henson DA, Shanely RA, Knab AM, Cialdella-Kam L, et al. Latent cytomegalovirus infection and innate immune function following a 75 km cycling time trial. Eur J Appl Physiol. 2013:113:2629-35.

8. Radak Z, Zhao Z, Koltai E, Ohno H, Atalay M. Oxygen consumption and usage during physical exercise: the balance between oxidative stress and ROS-dependent adaptive signaling. Antioxid Redox Signal. 2013;18:1208-46.

9. Powers SK, Lennon SL. Analysis of cellular responses to free radicals: focus on exercise and skeletal muscle. Proc Nutr Soc. 1999:58:1025-33.

10. Wang $Y J$, Wei $X Y$, Jing $X Q$, Chang $Y L, H u C H$, Wang $X$, et al. The fundamental role of NOX family proteins in plant immunity and their Regulation. Int J Mol Sci. 2016;17:805.

11. Marino D, Dunand C, Puppo A, Pauly N. A burst of plant NADPH oxidases. Trends Plant Sci. 2012;17:9-15.

12. Lushchak VI. Free radicals, reactive oxygen species, oxidative stresses and their classifications. Ukr Biochem J. 2015;87:11-8.

13. Valko M, Rhodes CJ, Moncol J, Izakovic M, Mazur M. Free radicals, metals and antioxidants in oxidative stress-induced cancer. Chem Biol Interact. 2006;160:1-40

14. Kim J, Park J, Lim K. Nutrition supplements to stimulate Lipolysis: a review in relation to endurance exercise capacity. J Nutr Sci Vitaminol. 2016:62:141-61.

15. Spriet LL. Regulation of skeletal muscle fat oxidation during exercise in humans. Med Sci Sports Exerc. 2002:34:1477-84.

16. Kitaoka Y, Takahashi Y, Machida M, Takeda K, Takemasa T, Hatta H. Effect of AMPK activation on monocarboxylate transporter (MCT)1 and MCT4 in denervated muscle. J Physiol Sci. 2014;64:59-64.
17. McFarlan JT, Yoshida Y, Jain SS, Han XX, Snook LA, Lally J, et al. In vivo, fatty acid translocase (CD36) critically regulates skeletal muscle fuel selection, exercise performance, and training-induced adaptation of fatty acid oxidation. J Biol Chem. 2012;287:23502-16.

18. Jordy AB, Kiens B. Regulation of exercise-induced lipid metabolism in skeletal muscle. Exp Physiol. 2014;99:1586-92.

19. Smith BK, Bonen A, Holloway GP. A dual mechanism of action for skeletal muscle FAT/CD36 during exercise. Exerc Sport Sci Rev. 2012;40:211-7.

20. Niu Y, Yuan H, Fu L. Aerobic exercise's reversal of insulin resistance by activating AMPKa-ACC-CPT1 signaling in the skeletal muscle of C57BL/6 mice. Int J Sport Nutr Exerc Metab. 2010;20:370-80.

21. Richmond SR, Carper MJ, Lei X, Zhang S, Yarasheski KE, Ramanadham S. HIV-protease inhibitors suppress skeletal muscle fatty acid oxidation by reducing CD36 and CPT1 fatty acid transporters. Biochim Biophys Acta. 1801;2010:559-66.

22. Bishop DJ, Granata C, Eynon N. Can we optimise the exercise training prescription to maximise improvements in mitochondria function and content? Biochim Biophys Acta. 1840;2014:1266-75.

23. Holloszy JO, Oscai LB, Don IJ, Molé PA. Mitochondrial citric acid cycle and related enzymes: adaptive response to exercise. Biochem Biophys Res Commun. 1970;40:1368-73

24. Ratzinger F, Haslacher H, Poeppl W, Hoermann G, Kovarik JJ, Jutz S, et al. Azithromycin suppresses CD4(+) T-cell activation by direct modulation of mTOR activity. Sci Rep. 2014:4:7438.

25. Cho I, Kim J, Jung J, Sung S, Kim J, Lee N, et al. Hepatoprotective effects of hoveniae semen cum fructus extracts in ethanol intoxicated mice. J Exerc Nutrition Biochem. 2016:20:49-64.

26. Kang EB, Cho JY. Effect of treadmill exercise on PI3K/AKT/mTOR, autophagy, and tau hyperphosphorylation in the cerebral cortex of NSE/htau23 transgenic mice. J Exerc Nutrition Biochem. 2015;19:199-209.

27. Antunes BM, Cayres SU, Lira FS, Fernandes RA. Arterial thickness and Immunometabolism: the mediating role of chronic exercise. Curr Cardiol Rev. 2016:12:47-51.

28. Wadley AJ, Aldred S, Coles SJ. An unexplored role for Peroxiredoxin in exercise-induced redox signalling? Redox Biol. 2016:8:51-8.

29. Li M, Li W, Yoon JH, Jeon BH, Lee SK. Resistance exercise training increase activation of AKT-eNOS and ref-1 expression by FOXO-1 activation in aorta of F344 rats. J Exerc Nutrition Biochem. 2015;19:165-71.

30. Steinbacher $P$, Eckl P. Impact of oxidative stress on exercising skeletal muscle. Biomol Ther. 2015;5:356-77.

31. Lee $K P$, Lee $K$, Park WH, Kim H, Hong H. Piperine inhibits platelet-derived growth factor-BB-induced proliferation and migration in vascular smooth muscle cells. J Med Food. 2015;18:208-15.

32. Bonen $A$, Han XX, Habets DD, Febbraio M, Glatz JF, Luiken JJ. A null mutation in skeletal muscle FAT/CD36 reveals its essential role in insulinand AICAR-stimulated fatty acid metabolism. Am J Physiol Endocrinol Metab. 2007;292:1740-9

33. Leek BT, Mudaliar SR, Henry R, Mathieu-Costello O, Richardson RS. Effect of acute exercise on citrate synthase activity in untrained and trained human skeletal muscle. Am J Physiol Regul Integr Comp Physiol. 2001; 280:441-7.

34. BrahmaNaidu P, Nemani H, Meriga B, Mehar SK, Potana S, Ramgopalrao S. Mitigating efficacy of piperine in the physiological derangements of high fat diet induced obesity in Spraque Dawley rats. Chem Biol Interact. 2014; 221:42-51.

35. Srivastava RA, Pinkosky SL, Filippov S, Hanselman JC, Cramer CT, Newton RS. AMP-activated protein kinase: an emerging drug target to regulate imbalances in lipid and carbohydrate metabolism to treat cardio-metabolic diseases. J Lipid Res. 2012:53:2490-514.

36. Foretz M, Taleux N, Guigas B, Horman S, Beauloye C, Andreelli F, et al. Regulation of energy metabolism by AMPK: a novel therapeutic approach for the treatment of metabolic and cardiovascular diseases. Med Sci. 2006; 22:381-8.

37. Hong HR, Jeong JO, Kong JY, Lee SH, Yang SH, Ha CD, et al. Effect of walking exercise on abdominal fat, insulin resistance and serum cytokines in obese women. J Exerc Nutrition Biochem. 2014;18:277-85.

38. Kim KJ, Lee MS, Jo K, Hwang JK. Piperidine alkaloids from Piper retrofractum Vahl. Protect against high-fat diet-induced obesity by regulating lipid metabolism and activating AMP-activated protein kinase. Biochem Biophys Res Commun. 2011;411:219-25. 
39. Matsuda D, Ohte S, Ohshiro T, Jiang W, Rudel L, Hong B, et al. Molecular target of piperine in the inhibition of lipid droplet accumulation in macrophages. Biol Pharm Bull. 2008;31:1063-6.

40. Park UH, Jeong HS, Jo EY, Park T, Yoon SK, Kim EJ, et al. Piperine, a component of black pepper, inhibits adipogenesis by antagonizing PPARY activity in 3T3-L1 cells. J Agric Food Chem. 2012;60:3853-60.

41. Kaleem M, Sheema, Sarmad H, Bano B. Protective effects of Piper nigrum and Vinca rosea in alloxan induced diabetic rats. Indian J Physiol Pharmacol. 2005;49:65-71.

Submit your next manuscript to BioMed Central and we will help you at every step:

- We accept pre-submission inquiries

- Our selector tool helps you to find the most relevant journal

- We provide round the clock customer support

- Convenient online submission

- Thorough peer review

- Inclusion in PubMed and all major indexing services

- Maximum visibility for your research

Submit your manuscript at www.biomedcentral.com/submit 